\title{
Long term Spatiotemporal Variability of Atmospheric Aerosol Parameters over Western Indian sites by Satellite Remote Sensing Measurements
}

\author{
Anil Kumar Satoliya ${ }^{1}$, B. M. Vyas ${ }^{2}$ \\ ${ }^{1}$ Department of Physics, M L Sukhadia University, Udaipur 313001, India \\ ${ }^{2}$ Department of Physics, M L Sukhadia University, Udaipur 313001, India \\ ${ }^{* 1}$ Corresponding author email: anilsatoliya@gmail.com
}

\begin{abstract}
Long term satellite observations over more than one decade of several aerosols parameters, i.e., AOD550 nm, AE, COT, UV-AI and ASA have been analyzed to describe their overall monthly and seasonally climatology over least explored region of Western Indian sites. It has been found that maximum aerosols loading characteristics of coarse aerosols of dust mineral origin in May and minimum aerosols values in December month at selected arid sites and semi-arid site. Aerosol variables in noon hours seem to their two time higher values than their fore-noon magnitude at all selected places. Observed findings may be interpreted in view of mixed effect of increasing accumulation of regional and local aerosols emission activities. An significant long term trend in aerosols variable of positive values of more 47\% in AE and 25\% in AOD $550 \mathrm{~nm}$ itself would be indicated due to the extra-enhancement in human made activities of more than $10 \%$ in term of population growth, population density, transportation vehicles, industries as the enhancement in local anthropogenic aerosols production sources specially over western arid sites. Thus, the abundance of fine size of anthropogenic aerosols is found to be systematically enhanced in the last decade, which is serious concern to both climate and air pollution change aspect over western Indian region also in similar to other Indian regions.
\end{abstract}

Keywords: Atmospheric aerosols, Thar Desert region, AOD $550 \mathrm{~nm}$, Angstrom Exponent, ASA, COT and UV-AI

\section{Introduction}

Atmospheric aerosols (a heterogeneous mixture system of comprised solid or liquid particles suspended in air) are now becoming an vital geophysical components of the our Earth by virtue of their important direct solar radiative effect, indirect perturbation on cloud condensation properties and the semi-direct effect of these global change in environment and climate of the Earth, such as global warming, air quality, human health and local abnormal weather conditions (visibility, haze, rainfall pattern) (Gunaseelan, et al., 2014; Satheesh et al., 2017; Ramachandran, S., 2018). 
Such varieties of direct, indirect as well as semi-direct aerosol radiative impacts on the Earth surface to top of atmosphere owing to scattering and absorption of incident solar shortwave radiation and out-going long-wave terrestrial radiation spectrum with atmospheric aerosols have profound significant impact on the Earth weather and climate change and indirectly modifying the various cloud macro-and micro-physical properties by warming the cloud itself by absorption of incident solar radiation (IPCC,2013). Therefore, investigations of the multi-optical and microphysical aerosols properties are crucial to specify their climate variability governing agent, air pollution and human health effect (Mhawish, et al., 2021). In the last two decades, several Earth Observing System (EOS) satellite remote sensors, such as MODerate-resolution Imaging Spectroradiometer (MODIS), Ozone Monitoring Instrument (OMI), etc., have been developed to retrieve several aerosol parameters such as, aerosol optical depth at 550nm(AOD $550 \mathrm{~nm}$ ), Angstrom Exponent over 470 to $660 \mathrm{~nm}$ (AE, 470-660 nm), Ultra-Violet Aerosol Index (UV-AI),Cloud Optical Thickness (COT), Aerosol Scattering Angle (ASA), etc., at different spatial-temporal scale resolutions (Remer, et al., 2008; Bilal, et al., 2017).

Among these, long term aerosol parameters most commonly derived from such spacecraft remote-sensing satellite observations, used in global energy budget calculations, is AOD $550 \mathrm{~nm}$. It deals to amount or fraction of incident light that is either scattered or absorbed by atmospheric particulate matter particles, which is integrated over the vertical column through the depth of the atmosphere. AOD $550 \mathrm{~nm}$ and UV-AI are dimensionless quantities, physically specify overall the product of the overall atmospheric submicron size particle number concentration and the particle-effective extinction cross-section (which accounts for particle either scattering and absorption or both mechanisms), assessed along an effective vertical atmospheric cross sectional path (Srivastava, et al., 2012). Here UV-AI, a measure of absorbing aerosols either by dust or soot type aerosols, is a quantity that exhibits the deviation of the spectral dependence of backscattered UV-radiation in an atmosphere comprising aerosols from a pure Rayleigh atmosphere (Parisi, et al., 2021).

AE parameter or alpha is often used as a qualitative indicator of aerosol particle size and it is a very helpful metric to distinguish the aerosol type (coarse or fine mode aerosols) and its origin too (i.e., natural or anthropogenic activities).Therefore, it is a widely well accepted for investigation of aerosols size distribution, when $\mathrm{AE}>1$ indicated the effectiveness of more fine size anthropogenic source aerosols while, $\mathrm{AE}<1$ referred to as more abundance of coarse size aerosols of dust aerosols as natural aerosol type. At the same time, ASA gives the physical information about the nature of scattering radiation process either backward scattering or forward scattering depending upon value of angle between incident and scattered photon beam path from available atmospheric constituent particles (Eck, et al., 1999; Sabetghadam, et al., 2020).

Although, atmospheric aerosols parameters are now becoming focal points as well as one of crucial significant variables for Earth climate modeling research, atmospheric pollution as well as perturbation in Earth's solar radiation budget investigation owing to their complex roles and their significant large uncertainties in atmospheric processes (IPCC, 2013). Even-than, there is not enough available information about their long-term trends of various macro physical and micro aerosols optical properties over different geographical regions over the globe, specifically over the Desert arid zone (Satheesh, et al., 2017; IPCC, 2013). 
In view of the above importance, numerous researchers have reported their investigations on long term changes in few aerosol parameters, i.e., AOD and COT only specifically on regional basis over some parts of Indian regions (Ramachandran, S., 2007; Dey, S. \& Di Girolamo, 2011;Balakrishnaiah, et al., 2012; Ramachandran, et al., 2012; Sreekanth, V., 2013; Mehta, et al., 2016; Srivastava \& Saran, 2017; Kumar, et al., 2018; Kumar et al., 2021; Payra et al., 2021). They showed their main findings about primarily an increasing trend in aerosol loading or enhancement in AOD 550nm values in the densely populated and industrialized region of hot aerosol regimes such as Indo-Gangetic Plain (IGP) region and Southern Indian regime along most heavily polluted, industrialized, highly populated of major urban major cities, such as Delhi, Kanpur,Varanasi, Lucknow, Bangalore, Mumbai, Chennai, Ahmadabad, etc.,(Kumar, et al., 2018 ; Kumar, et al., 2021; Payra, et al., 2021, more references also there in). Although the remarkable advancement in space technology over present decade has been made and gave an opportunity in aerosols understanding in depth due to availability of long term available aerosol data retrieved from space based multi satellites on board observations, there is still a lack of understanding about the long term aerosols loading variability of their optical and physical properties specifically over least explored Western Indian region, which is highly influenced by natural mineral dust aerosols activities along with in nowadays by anthropogenic activities too (Sharma \& Kulshrestha, 2017). In addition to the above, instead of focusing on a single parameter only, that has been conducted by earlier workers (Srivastava, et al., 2012; Sabetghadam, et al., 2020), the combination of simultaneous measured several aerosols parameters, i.e., AOD $550 \mathrm{~nm}$, AE, COT, ASA and UV-AI have been used to furthermore enhancement in depth understanding about the evaluation about long term characteristics aerosol loadings along with the main aerosol types over the tropical Thar desert arid and semi-arid locations situated in Western India.

Therefore, for the ever first time over Western Indian region nearby Thar desert and vicinity of central Great Indian Thar desert location, the long-term trends in several aerosol parameters have been undertaken as main objective of the present study by using satellites observations over the period from 2002 to 2017.

\section{2- Study Sites, Data and Method of Analysis}

\subsection{The study Sites:}

Nowadays, Aerosol characteristics in the Western Indian region have been expected to alter extensively with regard to aerosol sources from natural and anthropogenic activities (Kulshrestha \& Sharma, 2015). The location of observational sites in Rajasthan State over Western India extends from about $23^{\circ} \mathrm{N}$ to $30^{\circ} \mathrm{N}$ latitude and $69^{\circ} \mathrm{E}$ to $74^{\circ} \mathrm{E}$ longitude, which are displayed in Indian Map, as shown in Fig. 1. 


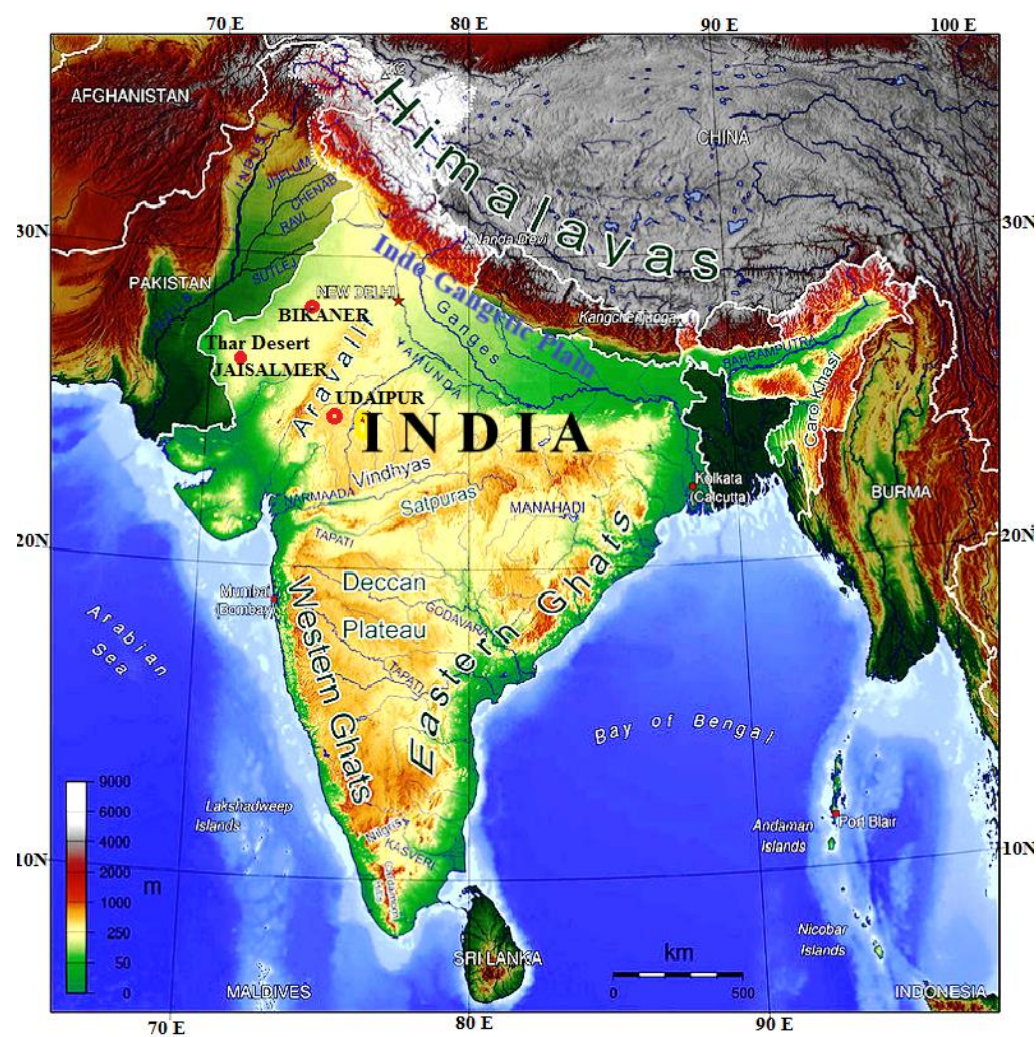

Fig. 1 Geographical Goggle Physical Map of Indian Subcontinent showing the observing sites.

The three main locations have been specifically selected due to predominance nature of desert dust aerosols influenced activities, which are either positioned over vicinity of central part of Great Western Indian Thar Desert site of arid rural stations (i.e., Jaisalmer (JSLM, $26.92^{\circ} \mathrm{N}, 70.91^{\circ} \mathrm{E} \& 225 \mathrm{~m}$ above mean sea level (asl)); Bikaner (BKN, 28.03 $\mathrm{N}, 73.31^{\circ} \mathrm{E} \& 242 \mathrm{~m}$ asl)) or slightly away from Thar desert as a semi-arid urban location, i.e., Udaipur (UDP, $24.58^{\circ} \mathrm{N}, 73.69^{\circ} \mathrm{E} \& 584 \mathrm{~m}$ asl)), as depicted in Fig. 1. Further more details of sites are given as below:

BKN: The geographical location of Bikaner $(\mathrm{BKN})$ has represented district area of $30,245 \mathrm{~km}^{2}$ with abundant with sandy soil types interspersed with dunes and distinct mineral dust activity region. It is located in northern part of Rajasthan state as well as in active middle part of Great Indian Thar Desert on its western site along with the Tropic of Cancer passing through its southernmost tip. BKN has a humn population of about 26.6 lakh with peak temperature reached up to $50^{\circ} \mathrm{C}$ and dip $\mathrm{RH}$ value about $10 \%$ in summer month with average rainfall of about $220 \mathrm{~mm}$. It also possesses unique several typical characteristics similar to almost JSLM, i.e., situated in the upwind direction in the Great Indian Thar Desert of western Indian site of dominance of strong mineral dust natural aerosols activities and also in western edge of IGP region of densely urbanized, heavy industrial and agricultural activities great concerned to hot spot anthropogenic aerosols activity region (Fig.1).It is also a typical hot and arid region with intense Aeolian activity and transport of aerosols by the strong SW-W summer winds with similar to JSM (April to June).Therefore, JSLM and BKN, both typical hot arid and rural locations, are suitable choice and region for both dust aerosol and mixed urban aerosol variability's studies (https://censusindia.gov.in). 
JSLM: It is the largest district of Rajasthan as well as one of the largest in the country, having an area of $38,401 \mathrm{~km}^{2}$. It is situated over western side of Rajasthan of Western India as well as in main central part of Great Indian Thar Desert regime. It is a typical tropical dry, sandy and hot climate rural site of human population of 6.7 lakh only with maximum ambient temperature of about $50^{\circ} \mathrm{C}$, wind speed up to $15 \mathrm{~m} / \mathrm{sec}$, $\mathrm{RH}$ values of less than $10 \%$ and scarcity of low annual total rainfall about $170 \mathrm{~mm}$ only.(https://censusindia.gov.in).

UDR: Udaipur $\left(24.6^{\circ} \mathrm{N}, 74^{\circ} \mathrm{E}, 580 \mathrm{~m}\right.$ asl $)$ is a typical semi-arid urban district and situated in most southern part of Rajasthan state of the northwestern part of India, having a population of around two million, spread in about $13,000 \mathrm{~km}^{2}$ only with highest air temperature of $44^{\circ} \mathrm{C}$ and lowest $\mathrm{RH}$ of $20 \%$ in pre-monsoon month with annual rainfall magnitude of about $600 \mathrm{~mm}$. It is also located quite near to tropic of cancer line. Despite being its semi-arid nature, $37 \%$ of its geographical area is forested (as per the Census of India, 2011) with vegetation typical to this environment. The location of UDP site is depicted in Fig. 1. The observational site is surrounded by Aravalli Mountain hill range as well as the Thar desert region on the one side to the North-West from UDP. Large numbers of marbles, granite, cement, and textile industries, zinc smelters and thermal power plants spreading from North to South-East direction within the circle of a radius $200 \mathrm{~km}$ of the place characterize its anthropogenic influence along dust activities influence mainly in summer months. Besides, the place is a well-known for the tourist attraction destination (http://www.censusindia.gov.in/ 152 2011census/ dchb/ DCHB_A / 08/ 0832_PART_A_DCHB_153UDAIPUR.pdf).

\subsection{Data and Method of Analysis:}

Satellite data of MODIS, OMI, etc., observations have been used to study the long-term aerosol variability and determine the aerosol type over selected western Indian tropical arid and semi-arid places. MODIS on-board payload of the special polar orbiting NASAEOS Terra and Aqua satellites gives aerosol related parameters globally started from 2000 and 2002, respectively. In the present study, the collection 6 MODIS aerosol data products (MODIS-Terra and AquaMOD08_D3_6) are utilized which are retrieved from the portal: http://giovanni.gsfc.nasa.gov/giovanni. Here, MODIS (Terra and Aqua) values are observed around at 10:30 hrs and 13:30 hrs, respectively, over respective observing sites. Aerosol retrievals from MODIS data are performed over land and ocean using separate algorithms thoroughly described in Remer, et al. 2006 \& 2008. Although, in the course of investigation, only, the deep blue algorithm from is used for aerosol retrieval over the region, which are compatible for land use investigation, as suggested by Mhawish, et al., 2021. Five concerned aerosol parameters as product, from the Collection 6 MODIS aerosol products, are being considered into account in the present study, including the aerosol AOD 550nm, AE (470/660 nm), UV-AI, ASA and COT. All these data have a spatial resolution of grid $1^{\circ}$ latitude $\times 1^{\circ}$ longitude (Kumar et al., 2021; Hsu et al., 2006). However, there are some gaps in the data, mostly during pre-monsoon and monsoon, which may due to the extent cloud cover and its contamination over study area.

Available daily data values are collected from 1 July 2002 to 31 December 2017 over the Western Indian Regime. But daily UV-AI variable is measured by from Total Ozone Mapping Spectrometer (TOMS) instruments carried on three polar on-board satellites (Nimbus 7 (N7) from January 1979 to June 1993, Earth Probe (EP) from July 1996 to December 2005 and OMI from January, 2004 to December, 2017. Such longer period 
observations of daily data have provided the best opportunity to study the long-term trend and over all annual monthly aerosol climatology over the study region. The combined each average monthly values of particular selected parameters with their standard deviation are computed after combining all specific particular months for the entire longer period of one decade or more. Such average combined annual monthly variation of all selected parameters over three specified sites for the complete study period have been represented in form of the histograms, as shown in Figs. 2-5(a-h) and Figs. 6(a-d). Their respective standard deviation values of each parameter are also depicted as vertical error bars on each monthly mean value of its histogram. Such monthly histogram have been furthermore displayed and grouped in the four following seasons as defined as: winter (December, January, February), Pre-monsoon (March, April, May, June), Monsoon (July, August, September) and Post-monsoon (October, November) to infer the seasonal dependence over the region.

In order to study the long-term trend in specified selected parameters over particular sites, the yearly average values are also computed for entire specified period. In this direction, variation of average yearly value of each parameter are plotted with function of their respective year, besides these, such annual mean time series of all chosen parameters are subjected to statistical linear regression analysis to evaluate trend analysis parameters such as slopes, correlation coefficients (r), etc., of the linearly fitted line. The best fitted linear regression line, line equation, annual mean values for entire observational period, $\mathrm{r}$ with a significance level over $95 \%$ only are also illustrated in respective figures., Figs. 7(a-h) and Fig. 8.

\section{Results and discussions:}

The annual monthly average variation of all considered aerosols parameters based on multiyear data are shown in Figs.2 (a-h) and Figs.6 (a-d). In this section, aerosol parameter's values retrieved from MODIS-Terra at 10:30 hrs are mentioned in the following order for BKN, JSLM and UDR, whereas in case of respective aerosol parameter's magnitudes related to MODIS-Aqua at 13:30 hrs of similar locations are written in similar order in bracket adjacent with aerosols parameters of MODIS-Terra. The details result of each aerosol parameters have been discussed in the forthcoming section based on the computed statistical parameters and plots as described below:

Table: 1 Complete statistics of Population, Population Growth, Population density, Number of Vehicles, Tourists and Industries of study period over three particular places.

\begin{tabular}{|l|c|c|c|}
\hline \multicolumn{4}{|c|}{ Population Growth in \% and Population Density in (inhabitants per $\mathbf{k m}^{\mathbf{2}}$ ) } \\
\hline & BKN & JSLM & UDR \\
\hline Population Growth 2001 & $32 \%$ & $24.39 \%$ & $24.27 \%$ \\
Estimated Population 2020 & $7,86,652$ & $7,76,972$ & $3,55,8754$ \\
Population Growth 2011 & $22 \%$ & $31.81 \%$ & $23.69 \%$ \\
Density/km ${ }^{2}$, 2001 & 46 & 13 & 196 \\
Density/km $/ \mathrm{km}^{2}, 2011$ & 78 & 17 & 262 \\
\hline
\end{tabular}




\begin{tabular}{|c|c|c|c|}
\hline & \multicolumn{3}{|c|}{ Number of Tourist Visit During the Year } \\
\hline YEAR & BKN & JSLM & UDR \\
\hline 2010 & 349699 & 388405 & 755313 \\
2011 & 352366 & 404128 & 753143 \\
2012 & 401485 & 199789 & 777612 \\
2013 & 400192 & 196490 & 847405 \\
2015 & 414392 & 342475 & 887056 \\
2016 & 409539 & 350708 & 892791 \\
2017 & 385544 & 450434 & 940404 \\
2018 & 418024 & 616606 & 1021305 \\
2019 & 456899 & 659101 & 1136947 \\
2020 & 413110 & 436543 & 1185246 \\
\hline
\end{tabular}

Source: - https://www.tourism.rajasthan.gov.in

\begin{tabular}{|c|c|c|c|}
\hline & \multicolumn{3}{|c|}{ Number of Industries Registered During The Year } \\
\hline YEAR & BKN & JSLM & UDR \\
\hline $2014-15$ & 790 & 250 & 860 \\
$2015-16$ & 790 & 250 & 860 \\
$2016-17$ & 830 & 263 & 903 \\
$2017-18$ & 2901 & 342 & 4646 \\
$2018-19$ & 4713 & 589 & 5000 \\
$2019-20$ & 6599 & 932 & 6058 \\
\hline
\end{tabular}

Source: - https://industries.rajasthan.gov.in/content/industries/doi.html

\begin{tabular}{|c|c|c|c|}
\hline & \multicolumn{3}{|c|}{ Number of Vehicles Registered During the Year } \\
\hline YEAR & BKN & JSLM & UDR \\
\hline $2014-15$ & 20755 & 7617 & 62153 \\
$2015-16$ & 25992 & 8208 & 60359 \\
$2016-17$ & 30862 & 9230 & 69514 \\
$2017-18$ & 35154 & 13294 & 66966 \\
$2018-19$ & 34698 & 5984 & 76131 \\
$2019-20$ & 37958 & 15955 & 79726 \\
$2020-21$ & 26489 & 7858 & 47722 \\
\hline
\end{tabular}

Source: -https://transport.rajasthan.gov.in

(i). The combined annual average monthly AOD $550 \mathrm{~nm}$ for MODIS-Terra and Aqua case, i.e., forenoon and after noon hours at 10:30 and 13:30 hrs over BKN, JSLM and UDR, as shown in Figs. 2(a-h) showed the systematic increasing trend after attaining the minimum values of $0.39 \pm 0.24 ; 0.36 \pm 0.15 \quad \& \quad 0.32 \pm 0.22 \quad(0.4 \pm 0.25 ; 0.27 \pm 0.10 \quad \&$ $0.33 \pm 0.23)$, respectively, in February, March and October. After that, their respective maximum AOD $550 \mathrm{~nm}$ values related for both cases of MODIS in same sites are found in the values of $0.87 \pm 0.42 ; 0.84 \pm 0.35 \& 0.63 \pm 0.32(0.61 \pm 0.19 ; 0.73 \pm 0.32 \& 0.63 \pm 0.38)$, respectively, in July. It is clear from the above that highest aerosols loadings in about two time folds are always noticed in July in arid desert sites as well as at semi-arid site in both cases of AOD $550 \mathrm{~nm}$ (Terra and Aqua). Moreover, their particular MODIS-Terra's AOD magnitudes at 13:30 hrs are always to be noticed in higher side of 50\% more than to their MODIS-Aqua AOD $550 \mathrm{~nm}$ values. Thus, noontime aerosols loadings are higher than their fore noon aerosol burdens. However, their overall combined annual mean AOD $550 \mathrm{~nm}$ values of forenoon (MODIS-Terra) and afternoon hours (MODIS-Aqua) values are also showed in the similar features as evident from respective MODIS-Terra 
related values over BKN, JSLM \& UDR of $0.96 \pm 0.21,0.80 \pm 0.19 \& 1.15 \pm 0.10$, respectively, and respective MODIS-Aqua's magnitude of $1.06 \pm 0.21,0.92 \pm 0.25$ and $1.23 \pm 0.13$, respectively, for the period from 2002 to 2017 .
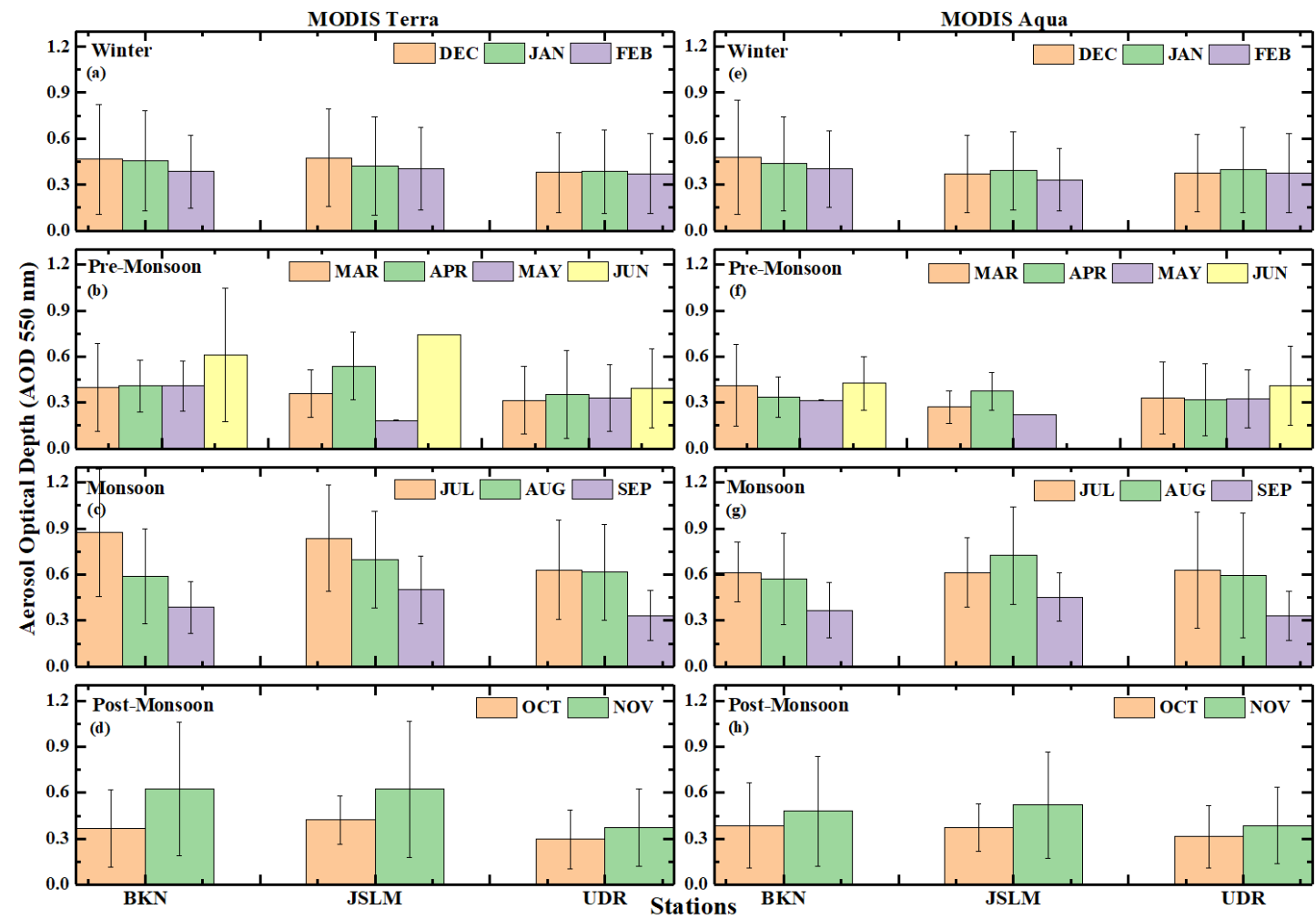

Figs. 2(a-h) Combined monthly variations of AOD 550nm over three sites for 15 years

Therefore, it is interesting to note that such peak AOD $550 \mathrm{~nm}$ values of 0.95 over arid and semi-arid sites are noticed to be slightly lesser than relative to their reported Delhi's value of around 1.2 (Kumar et al., 2021). Moreover, the annual AOD $550 \mathrm{~nm}$ values seems to be changed in the accordance with corresponding alteration in human population density, anthropogenic activities concerned to number of industries, tourist activities, etc., over the measuring places over different years, as seen from Table:1. In this line, annual combined mean AOD $550 \mathrm{~nm}$ values for the 15 years have been found to be highest AOD's value in UDR along with respective higher value of human population, population density, number of vehicles, industries, tourists, etc., intermediate value of AOD 550nm at BKN with all respective corresponding values related to population, population density, number of industries, tourists and registered vehicles and lowest AOD value along with all mentioned anthropogenic influenced parameters as shown in Table:1, at JSLM. However, the nature of monthly as well as seasonal variation in AOD $550 \mathrm{~nm}$ seems to quite similar pattern as obtained in present study with comparison to other Indian stations also, but discrepancies have been noticed in their magnitude values only, which may again depend upon the human made activity factors of observing sites (Balakrishnaiah et al., 2012, more references are therein).

(ii). Figs.3(a-h) illustrate the overall month to month average behavior in AE for the period 2002 to 2017 over the three locations. It has been observed that lower values of $\mathrm{AE}$ in case of MODIS-Terra (Aqua)) over BKN, JSLM \& UDR are 0.47 \pm 0.45 ; 
$0.38 \pm 0.41 \& 0.65 \pm 0.51,(0.62 \pm 0.52,0.52 \pm 0.51 \& 0.79 \pm 0.53$. $)$, respectively. However, their such respective maximum mean monthly $\mathrm{AE}$ magnitude of the similar sites are noticed to be equal to $1.32 \pm 0.43,1.11 \pm 0.53 \& 1.46 \pm 0.27(1.42 \pm 0.34,1.25 \pm 0.48 \& 1.49$ $\pm 0.19)$, respectively, in December and January. The above observations itself indicated the lower $\mathrm{AE}$ values < 1 in May of predominant abundance of bigger size or coarse type as dust aerosols in desert influenced period, whereas in case of higher $\mathrm{AE}>1$ magnitude gave the support about dominance of fine size of anthropogenic aerosols in December and January or in winter season over observing sites.

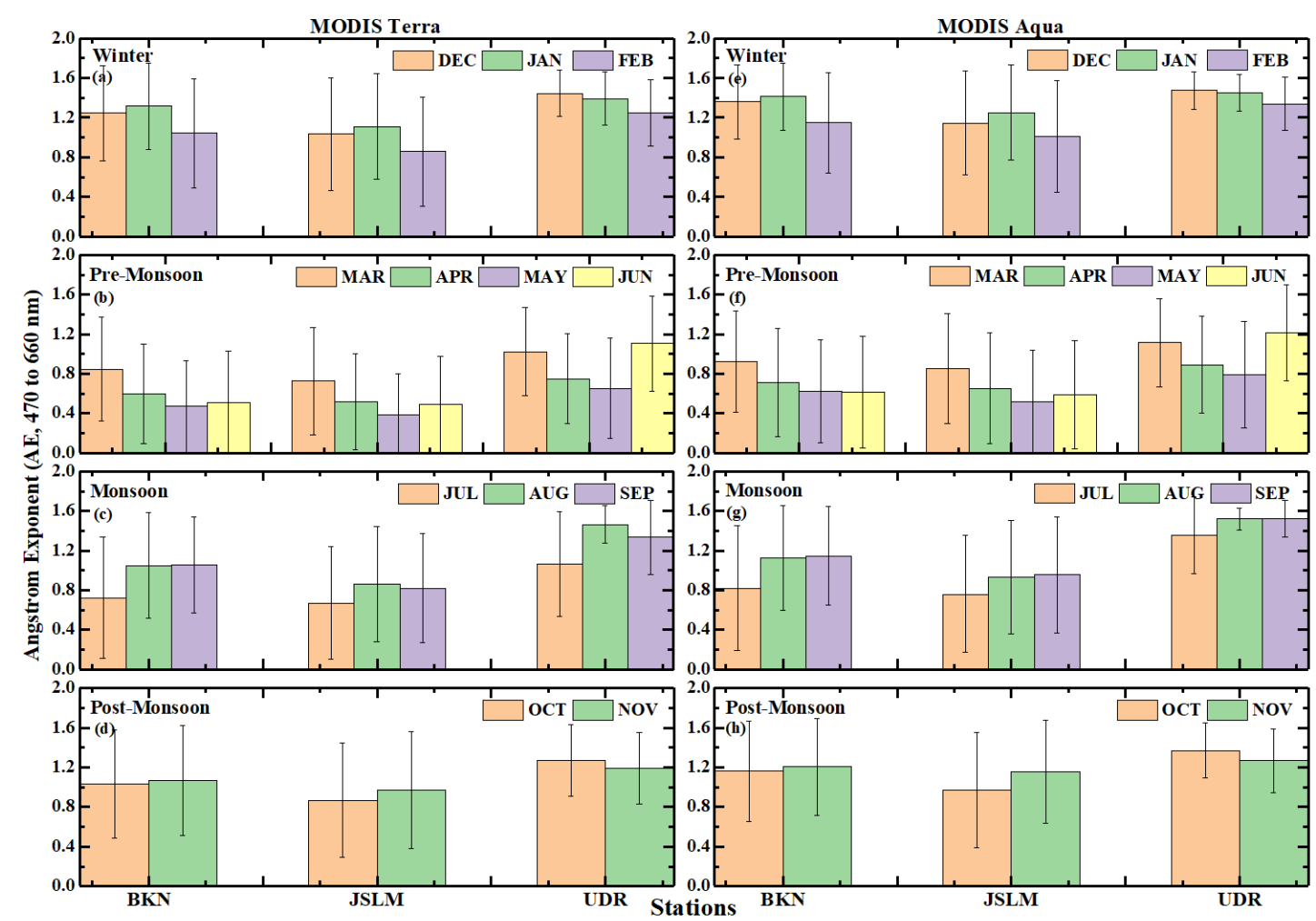

Figs. 3(a-h) Overall monthly dependence of AE over three locations for 15 years

However, the minimum and maximum $\mathrm{AE}$ monthly values have been seen to systematically enhanced from JSLM to UDR through BKN, i.e., as shift from Central Thar Desert Arid site to away from the Desert site of semi-urban location. It may be attributed furthermore due to either possible cause of enhancement in anthropogenic aerosols loadings or reduction in natural mineral dust aerosols activities in accordance with shifting of observing sites from JSLM to UDR through BKN. The monthly as well as seasonal dependence of AE over various other parts of Indian subcontinent have been also reported comparable pattern as observed in this study, so far. But, again the deviation in values are seen which are quite higher magnitude of leading to excess anthropogenic activities as reported over other major Indian Urban and Metro cities relative to present observational rid and semi-arid sites, which could be again expected to be linked by excess human made activities source of fine size aerosol over other Indian locations of densely populated, highly industrialized activities as well as agricultural human made activities (Ramachandran, S., 2007; Babu et al., 2013; Sreekanth, 2013; Srivastava, et al., 2017; Satheesh, et al., 2017;Ramachandran, S., 2018). 
(iii). In regard to annual mean monthly change in UV-AI based on 36 year observation period collected by different multi-polar satellite sensors, such as TOMS NIMBUS-7 (period 1978-1996), TOMS EP (period 1996-2005) and OMI (period 2004-2017), it is noticed from plotted monthly histogram based on season wise of all three particular locations in Figs. 4(a-d) that the mean monthly UV-AI values over UDR as semi-arid site slight away from main desert influenced region in NW direction systematically enhance from a minimum value of around $0.77 \pm 0.26$ in February onward (indicated presence of weak absorbing aerosol or lesser dust activities region) and attained their peak dust absorbing value of about $1.42 \pm 0.7$ in May (slightly strong absorbing aerosols as main peak dust influenced month), afterward systematically reducing from $1.39 \pm 0.7$ to $0.79 \pm 0.27$ during June to January. In case of BKN and JSLM, the combined average monthly variations in the UV-AI are noticed comparable analogous pattern as observed over UDR. However, the UV-AI over Thar Desert arid region, i.e., BKN \& JSLM were seen to be attained their peak magnitudes in range of $(2.33 \pm 0.9$ to $2.35 \pm 0.89$, i.e., supporting the favorable evidence of accumulation of strong absorbing aerosols associated with primary mineral dust aerosol source region) in May and June, in between values $(1.16 \pm 0.47$ to $1.96 \pm 0.88)$ during July to September and March to April and the lowest magnitude in post monsoon and winter $(0.89 \pm 0.4$ to $1.09 \pm 0.38)$.
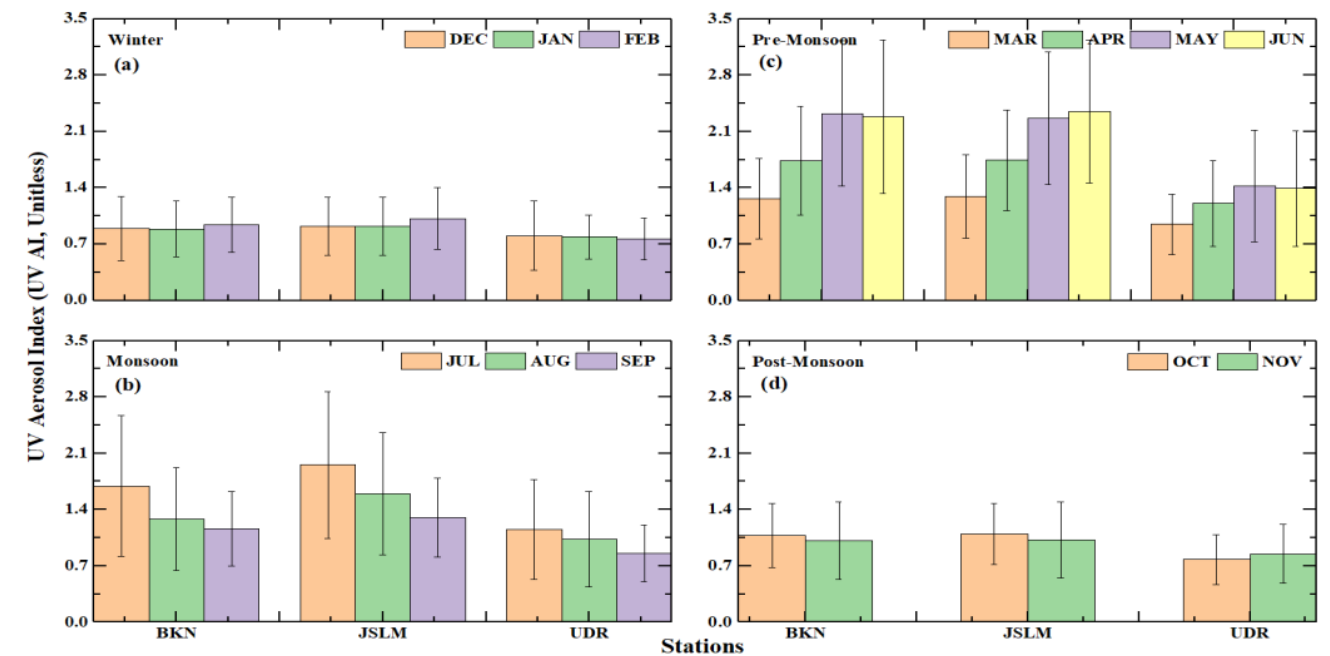

Figs. 4(a-d) Combined monthly change in UV-AI over three sites for 36-year data.

Thus, difference in UV-AI values between arid desert sites to semi-arid site is around 1.46. This may be well explained on the basis of argument of more extra availability and generation of dust mineral aerosols at arid sites, as main source origin locations relatives to semi-arid site, which may be attributed by predominance of weak aerosols types and lesser abundance of desert aerosols at UDP. Furthermore, overall annual mean UV-AI values for 36 year data for BKN, JSLM and UDR have been also systematically reduced from $1.41 \pm 0.27,1.5 \pm 0.27 \& 1.05 \pm 0.2$, respectively, as we shift from main Thar desert place (JSM) to away from desert influenced region, i.e., UDP. It clearly indicated that the strong absorbing aerosols are more loaded or available over BKN and JSLM, i.e., arid Thar desert region and weak absorbing aerosols as a lesser abundance of Aeolian activity at UDR. These observations are well supported and in accordance with earlier reported study of Al-Zuhairi, et al., 2021. Their observation pointed that UV-AI magnitude $<1.0$ indicated weak absorbing aerosol, whereas UV-AI $>1.1$ showed the presence of dust aerosol as strong absorbing UV aerosol radiation agent. 
(iv).The combine annual average month to month variation in COT for the 15year period, from 2002 to 2017 is represented in the form seasonal histograms for three preferred observational sites, as seen in Figs. 5(a-h). It is quite clear evident that the lowest monthly COT values over BKN, JSLM and UDR from MODIS-Terra (Aqua) observations are found in order of $3.87 \pm 5.07,4.3 \pm 7.33 \& 4.46 \pm 6.03$, respectively, $(14.63 \pm 7.61,5.06 \pm 7.52 \& 2.95 \pm 3.5$, respectively, ) in December. However, the higher COT magnitudes over BKN, JSLM \& UDR from MODIS-Terra(Aqua) measurements are observed in magnitudes of $8.93 \pm 8.45,6.61 \pm 5.41 \& 24.79 \pm 20.61$, respectively, $(17.01 \pm 16.39,13.52 \pm 16.07 \& 10.5 \pm 13.4$,respectively,) in May to June and 8.27 \pm 9.4 , $8.42 \pm 7.7 \& 16.91 \pm 15.10$,respectively, $(14.45 \pm 15,16.19 \pm 18.28 \& 16.48 \pm 13$, respectively) either in October or August.

From the above analysis, it is obvious that the minimum average monthly COT magnitudes are noticed in a range from about 3 to 6 in December or cold period over both arid and semi-arid places. However, their maximum monthly COT values from MODIS -Terra \&Aqua have been seen in the higher ranges of 4 to 8 to 10 to 17 , respectively, in May and June over the study places. In addition to this, the higher monthly magnitudes are seen about 8 and 17 in arid and semi-arid site, respectively as well as also in October month in case of MODIS-Terra. Although in case of MODISAqua, such peak values between 14 to17 have been also seen in October over arid sites and in August in semi-arid place. Hence, such peak COT magnitudes in May and October have been found to be greater than two time folds relative to dip values in December over arid and semi-arid site. Furthermore, afternoon hrs (at 13:30 hrs) COT values concerned to MODIS-Aqua seem to be remained in higher side relative to their forenoon hrs. (10:30 hrs) COT values in most of arid as well as semi-arid site.

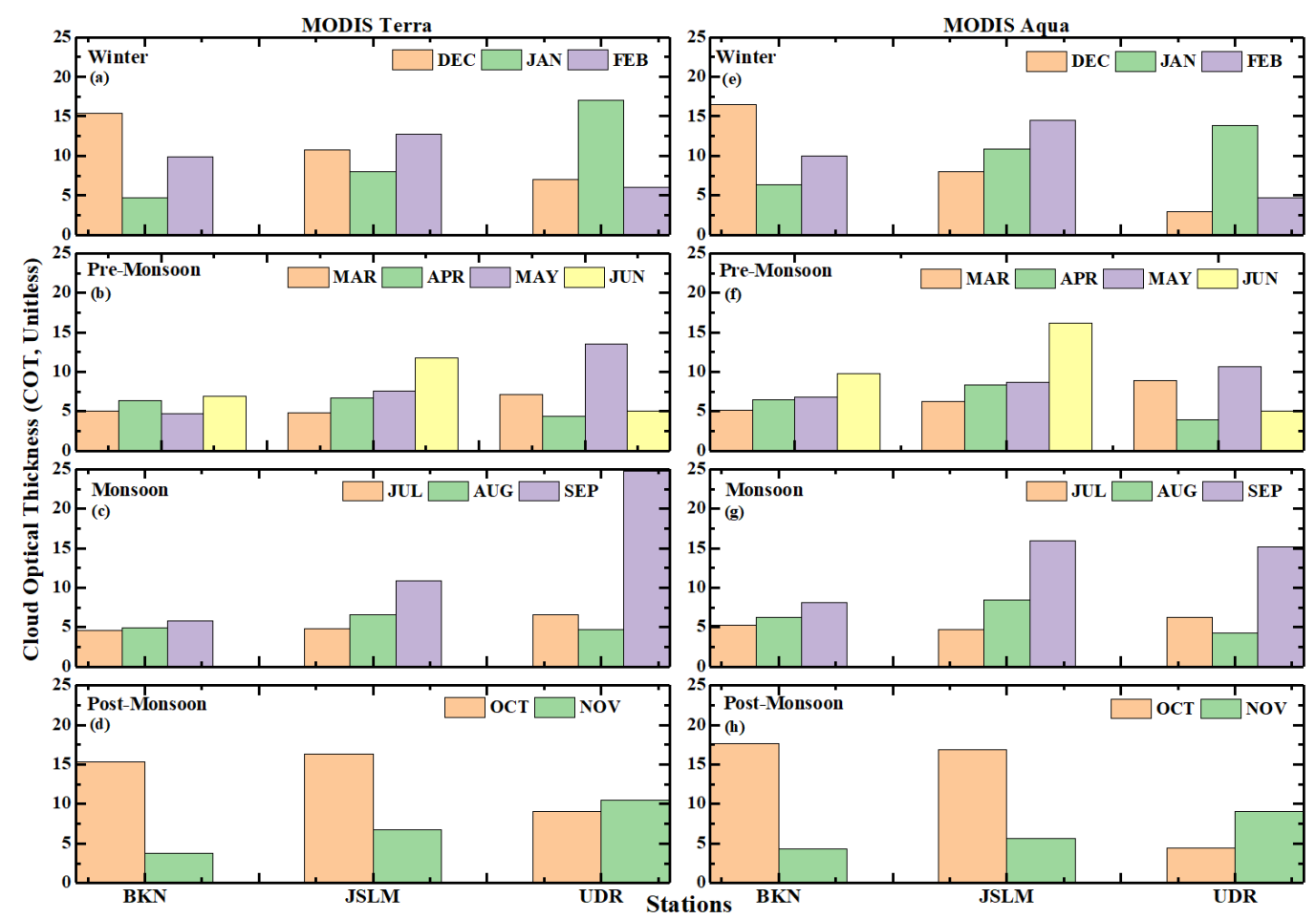

Figs. 5(a-h) Histograms show monthly behavior of COT at three sites for 15 year data. 
Similar observations concerned to COT annual mean magnitudes of MODIS-Aqua are noticed to be $9.8 \pm 0.68,8.45 \pm 0.72 \& 14.72$ over BKN, JSLM and UDR, whereas in case of MODIS-Terra the respectively. The corresponding annual COT values are $6.06 \pm 0.61$, $5.39 \pm 0.59 \& 10.95$ over BKN, JSLM \& UDP, respectively, which also seems to be higher values in case of MODIS -Aqua relative to their respective corresponding MODIS-Terra values case.

(v). Figs. 6(a-h) illustrate the combined annual average monthly variation of ASA in seasonal basis over three selected observational sites for the period of 15 year. It is seen that monthly variation of ASA measured by MODIS-Terra and Aqua sensor always showed the peak ASA values $\sim 144^{\circ}$ in June month and dip values $\sim 119^{\circ}$ in December over all selected places. Hence, more predominant nature of atmospheric backward scattering mechanism due to aerosols has been more prevalent in June relative to as observed in December.

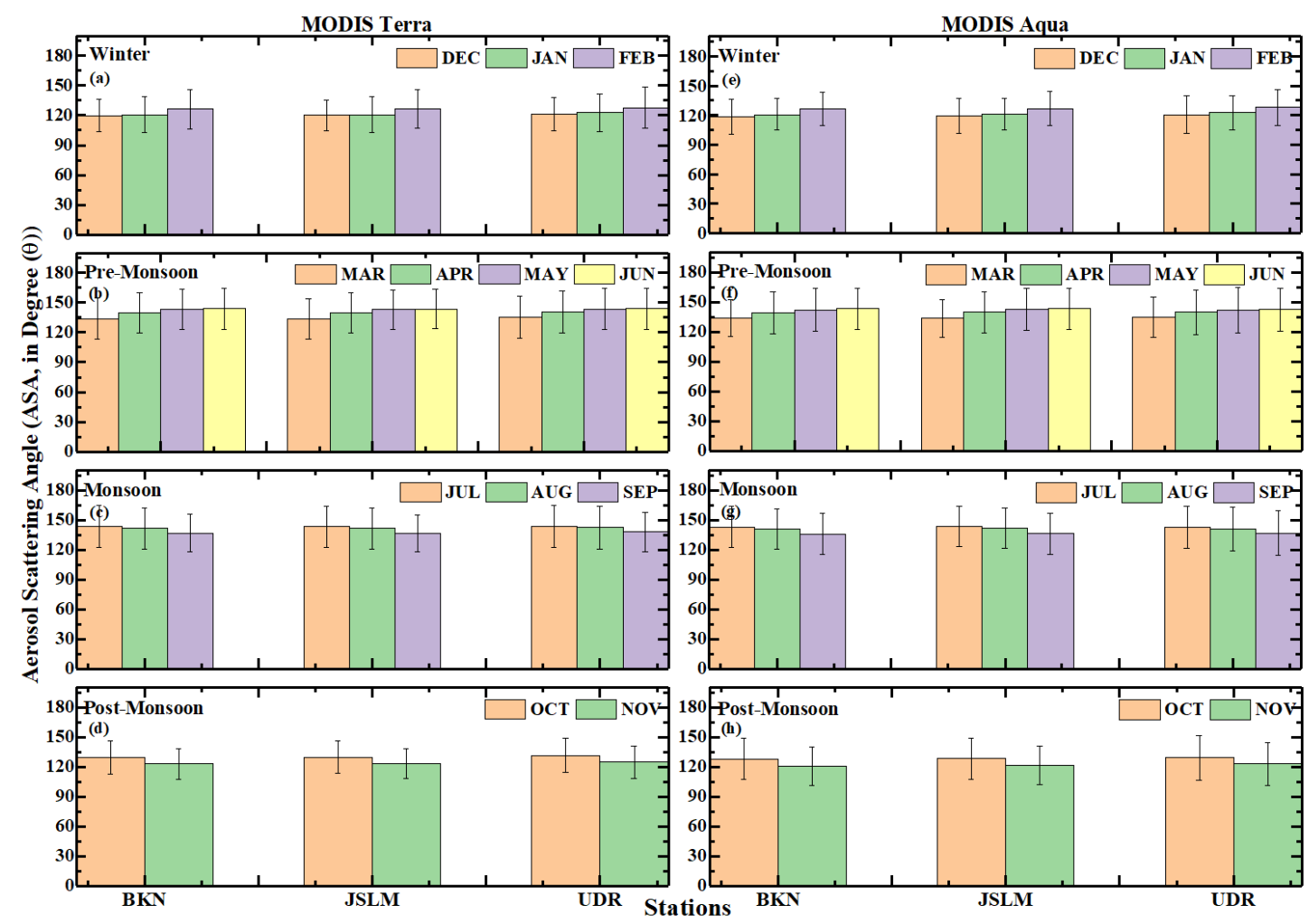

Figs. 6 (a-h) Combined monthly change in ASA at three sites for period 2002 to 2017.

Hence, the incident solar radiations have been attenuated primarily by backward scattering mechanism in atmosphere over arid and semi arid place, resulting as one of the main leading causes of alteration in earth solar radiation budget in atmosphere due to aerosols. Furthermore, above result may be more confirmed and supported by comparing computed overall annual ASA values over BKN, JSLM and UDR for MODISTerra(MODIS-Aqua) which are $133.59 \pm 0.11^{\circ}, 133.62 \pm 0.16^{\circ} \& 134 \pm 0.31^{\circ}$, respectively $\left(132.72 \pm 0.11^{\circ}, 133.20 \pm 0.20^{\circ} \& 133.50 \pm 0.11^{\circ}\right.$, respectively).

(vi).The long-term trends in selected aerosol parameters, i.e., ASA, AE, AOD 550nm, COT and UV-AI over the three sites are shown in Figs. 7(a-d) and Fig.v8. As far as concerned to long term change trend in ASA from the plot of yearly mean ASA values with respect to year, as depicted in Fig.7a, it is quite obvious that there is a minor 
statistically significant in long-term change of ASA observed about 7\% per decade over arid sites only. But, percentage decadal change in ASA over UDP is insignificant, i.e., $4 \%$. The overall mean values as shown in the plot lie in between $133^{\circ}$ to $135^{\circ}$ for arid desert and semi-arid location, as seen from their annual mean values in Fig.7a.Hence, the mechanism of reduction of incident useful solar radiation did not change and remain the same within 15 years observational period, which is nature of backward scattering of incident solar radiation by presence of atmospheric aerosols as air borne particulate matters over arid and semi-arid place.

The long-term trend in AE over three selected sites for 15 years are shown as variation of yearly mean values plotted with function of years that is revealed in Fig. 7(b). It is quite interesting to be noticed at here that decadal changes in AE from MODIS-Terra observations showed the most significant percentage variations of highest value $47.92 \%$ and $46.25 \%$ at BKN and JSLM and their lowest value of $19.13 \%$ at UDR. Such corresponding decadal percentage variation in AE values for MODIS -Aqua are noticed to be in maximum values of $47.92 \%$ and $55.43 \%$ at JSLM \& BKN and minimum value of $17.89 \%$ at UDR. It is obvious from the above results that enhancement of higher percentage decadal change in AE parameter above $47 \%$ at arid locations and lower value of 17 to $19 \%$ over semi-arid site.

It may be well explained on the basis of leading causes of extra enhancement in anthropogenic human made activities growth in term of population growth, population density, total number of registered vehicles, industries and tourist, etc., during last decade over three stations as shown in tabular form in Table:1. During 2001 to 2011, the population growth as well as population density values varied from 24.39 to $31.81 \%, 22$ to $32 \%$ and 23.69 to $24.27 \%$ at JSLM, BKN and UDP, respectively, whereas, population density values increase from 13 to 17 people km-2 at JSM, 46 to 78 people $\mathrm{km}^{-2}$ at BKN and 196 to 262 people $\mathrm{km}^{-2}$ at UDP. Similarly, with available data of number of registered vehicles and industries ( here shown in brackets) during 2014 to 2020 are systematically enhanced from 60288, 185419 and 414849 and $(2626,16623 \& 18327)$, at JSLM, BKN \& UDP, respectively. The total number of tourists during 2010 to 2020 are also increased from 42 lakh, 41 lakh and 92 lakh at JSM, BKN and UDP, respectively, with increasing of 1 lakh increasing per year. As the results of rapidly increasing in appreciable amount of enhancing anthropogenic emission activities as discussed above in light of human made activities factor which is the lowest in JSM, intermediate in BKN and highest at UDP may be inferred as one of probable cause of extra aerosols loading concerning to leading human made relative aerosols as local anthropogenic emissions activity.

At the same time, another possible reason of increasing fine size aerosols activities of aerosols loading could also be recognized due to transportation of aerosols owing to large scale atmospheric wind circulation phenomena, known as long range aerosols transportation phenomena, from heavy polluted region situated from far away from receptor sides, as suggested by Sen et al., 2017 from their study conducted over nearby various Indian locations. Hence, at this juncture, long term and short term increasing in anthropogenic aerosols at observing during the study may be well explained in light of corresponding mixed effect of altering extra local as well as regional aerosols emission activities. 
Nevertheless, overall combined annual average AE over 15year study period is $0.96 \pm 0.21,0.80 \pm 0.09$ and $1.15 \pm 0.10$ over BKN, JSLM and UDR, respectively, as computed from MODIS-Terra measurements. Whereas, in case of MODIS Aqua, such respective computed corresponding AE magnitudes are slightly in higher side values of $1.06 \pm 0.21,0.92 \pm 0.25$ and $1.23 \pm 0.13$, respectively. It also further more give the conformation and support in view of the above line.

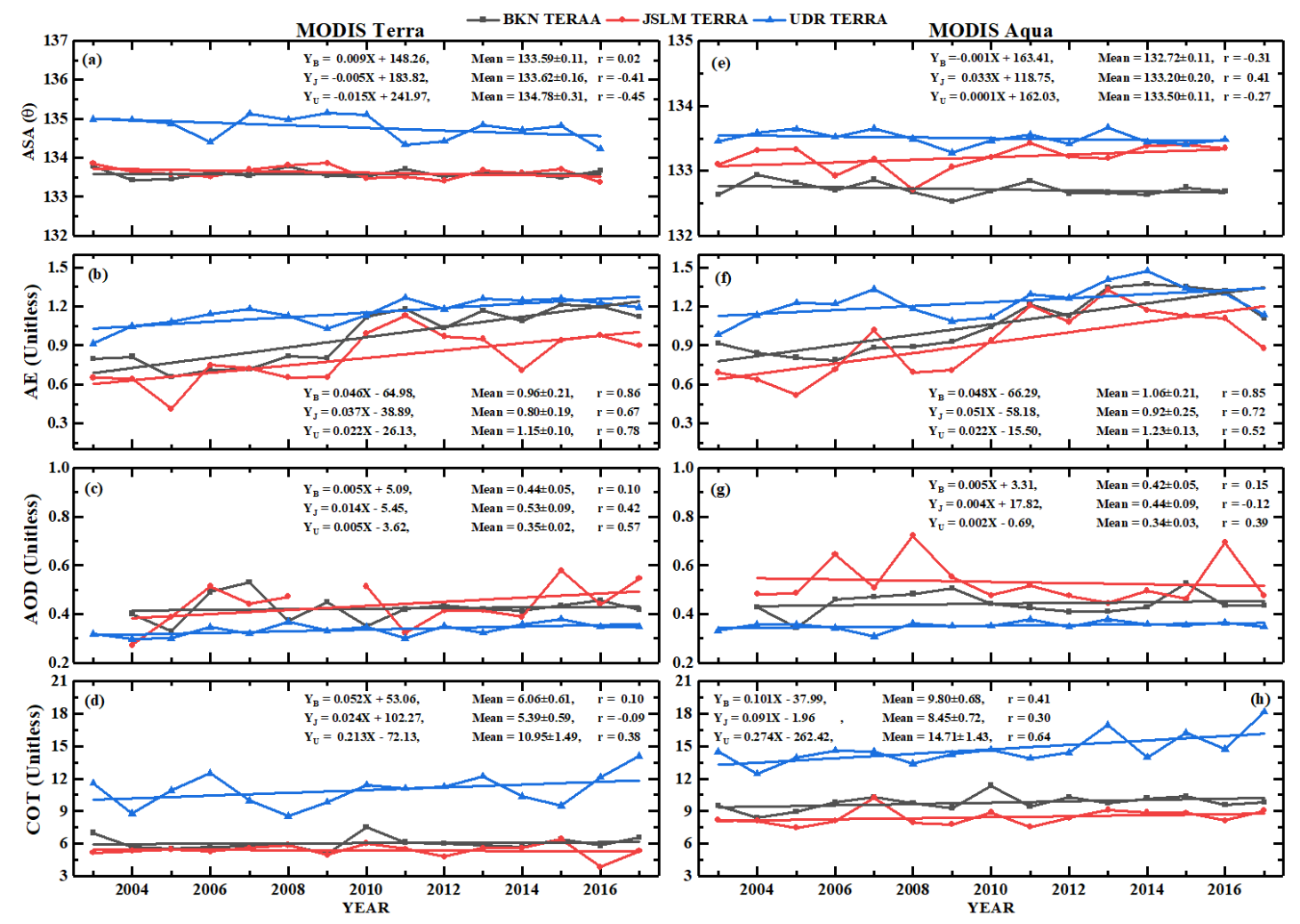

Figs. 7(a-h) Long term trend in ASA, AE,AOD \& COT at three sites for 15 year data.

As discussed earlier that $\mathrm{AE}$ values above 1 indicated more abundance of fine size anthropogenic aerosol, whereas $\mathrm{AE}$ below 1 revealed the tendency more presence of coarse size natural activities generated aerosols types, hence, from the above discussions, two facts are clearly emerging from the present investigation, (i) tendency of enhancement in local and regional anthropogenic activities more over Thar Desert site relative to Semi-Urban site which are implying from observed higher decadal change in AE over BKN and JSLM as compared to UDR. (ii) overall presence of inherent characteristics of more coarse type aerosol loading associated with mineral dust activities over arid desert region, as suggested by Pyara et al., 2021; Srivastava, et al., 2012; Kulshrestha \& Sharma, 2015, Sharma \& Kulshrestha, 2017, Sen, et al., 2017.

Figs.7c displayed year to year annual average AOD550 $\mathrm{nm}$ over the measured period from 2002 to 2017 over all three chosen sites. It is noticed from plot that an significant positive percentage variation in AOD 550nm has been detected in maximum value of $26.42 \%$ and $14.29 \%$ at JSLM and UDR and minimum value of $11.36 \%$ at BKN in case of MODIS-Terra observation. Whereas in case of MODIS-Aqua measurement, the respective magnitude occurred in the lower statistically significance value ranges from 
11.36 to 14.29 at BKN \& UDR, however, it noticed in a good statistically significant change level of $26.42 \%$ at JSLM. Hence, overall, there is a slightly long-term change in increasing aerosols loading nature which is higher at JSM and lower at UDP and BKN. While comparing their respective combined annual average mean AOD 550nm for MODIS-Terra are $0.44 \pm 0.05,0.53 \pm 0.09$ and $0.35 \pm 0.02$ over BKN, JSLM \& UDP, respectively. Whereas in case of MODIS-Aqua, such respective mean values are $0.42 \pm 0.05,0.44 \pm 0.09 \& 0.34 \pm 0.03$, respectively, which are again found more over arid sites relative to semi-urban site. The possible cause of excessive aerosols loading characteristics over arid sites would be also explained in light of excessive source of mineral dust activities over arid location as main source region relative semi-arid site, i.e., UDP.

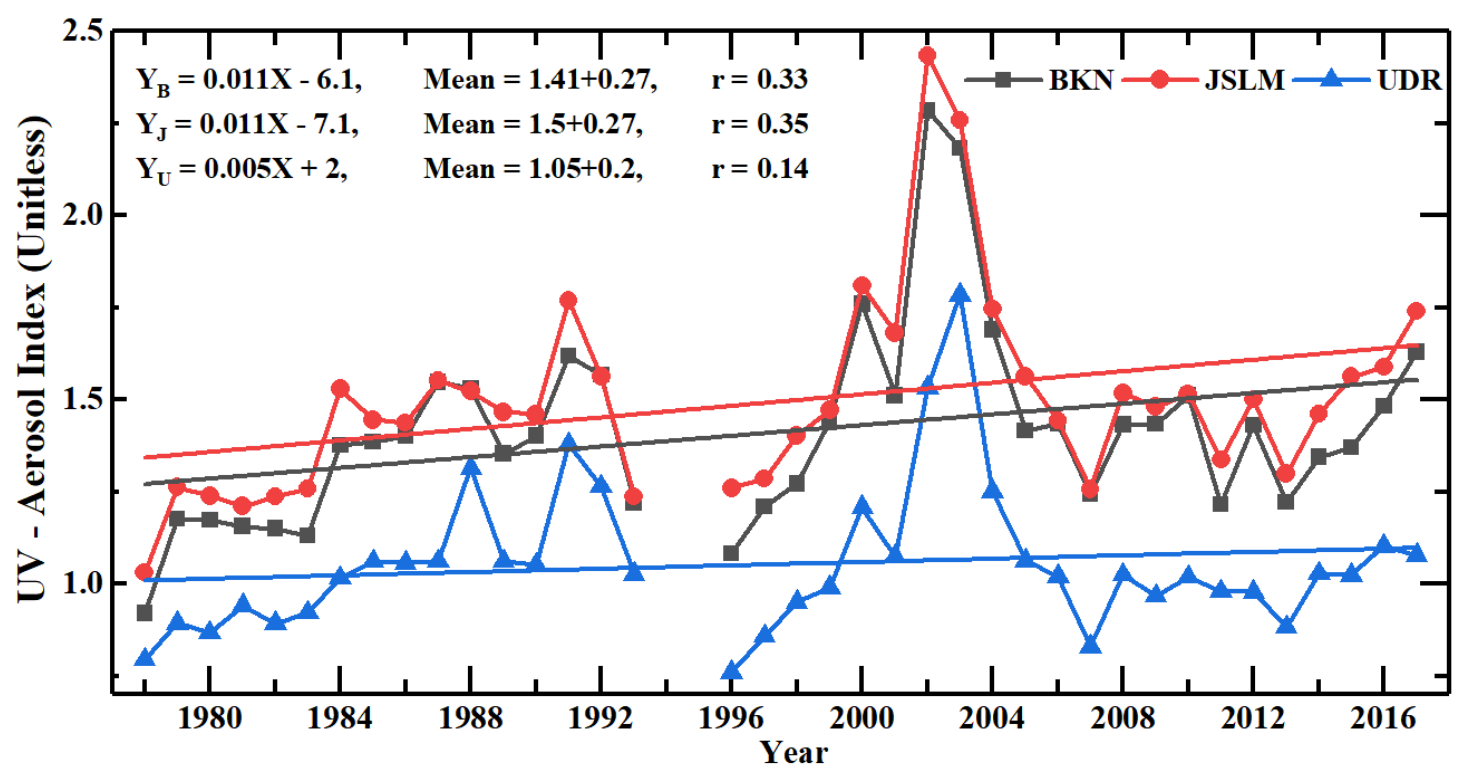

Fig.7. Long term change in UV-AI over three sites for period from year 1978 to 2017

The long-term change in AOD $550 \mathrm{~nm}$ analysis depicted the enhancement in aerosols loading behavior more serious over BKN \& JSLM, while comparing the UDP's results which has given clear scientific evidence of extra anthropogenic aerosols activities over measuring locations leading to possible reasons of increasing the man-made activities during observation period over measuring sites.

As far as concerned to long term change in UV-AI over arid places and semi arid site over 36 years observation, as shown in Figs 7, it is obvious that the increasing trend in UV-AI have been observed to be more prevalent in values of about $7 \%$ per decade in arid sites and its magnitude reduced to $4.76 \%$ at arid which is in accordance with changing the dust aerosol source level from the desert central region, i.e. JSM to UDP.

\section{Conclusions.}

All selected parameters leading to atmospheric aerosols parameters, such as AOD550nm, COT, ASA and UV-AI magnitudes have been shown primarily their maximum values in May and minimum values in December at arid places and semi-arid site located in Western India regime. However, their values are more over Thar Desert arid sites than 
semi-arid site. One of the interesting scientific feature is an increasing aerosol activities which is more visible and relevant over arid site as the possible cause of results of extra local and regional human activities across over Thar Desert area, which would lead to greater concern of more serious scientific issue in the present context over least explored western Indian regime too. As far as concerned to aerosol types and their sources, it is obvious from the average monthly climatology of AE pattern that predominant nature of desert aerosols type are more prevalent in summer month and lesser in winter over both the places. Hence, lower seasonal AE magnitudes of coarse aerosol type in summer is more predominated in near or in central region of desert area, i.e. BKN \& JSLM than UDP , i.e., away from Aeolian region. A systematic reliable positive per decadal change in $\mathrm{AE}$ and $\mathrm{AOD} 550 \mathrm{~nm}$ may lead definitely clear evidence of enhancement in anthropogenic fine sized aerosols loadings more over arid sites in special reference to surplus human made activities of local and regional sources in last decade. The cloud cover is seen more about double values in May and October than in winter over arid and semi-arid site. One of interesting features emerge from their ASA values observed for 15 year period over arid and semi-arid location that nature of mechanism of reduction in solar radiation intensity may be remained the same by atmospheric back scattering process of incident photon beam with presence of atmospheric aerosols. The long term trend of UV-AI index concerned to dust aerosols seems to be enhanced $\sim 7 \%(\sim 1.0$ to 1.75) over arid sites and 4.76\% (0.75 to 1.2) at UDP during the period 1978 to 2017 for a base value of $\sim 1.0$ in arid site and 0.75 at UDP with certain peak in great drought year 2002 over Western India

\section{Acknowledgement}

One of author AKS is grateful to UGC, New Delhi to provide a full financial assistance under the BSR fellowship. BMV is highly indebted to Indian Space Research Organization (ISRO), Bangalore for exchanging full scientific views for carrying out the present research work under Aerosol Radiative Forcing over the India (ARFI) research project under its ISRO-Geosphere Biosphere Program (ISRO-GBP). The authors also feel sincerely grateful to Prof. K. Krishanamoorthy, Ex-Director, SPL, VSSC, Thiruvananthapuram, Kerala, India and Dr. S Suresh Babu, Project Manager, ARFI Research Project, SPL, VSSC, Thiruvananthapuram, Kerala India for their academic and constant encouragement during the entire study period.

\section{References}

[1] Babu, S.S., M. R. Manoj, K. Krishna Moorthy, Mukunda M. Gogoi,Vijayakumar S. Nair, SobhanKumar Kompalli, S. K. Satheesh, K. Niranjan, K. Ramagopal, P. K. Bhuyan, and Darshan Singh, 2013, Trends in aerosol optical depth over Indian region: Potential causes, and impact indicators, J. Geophys. Res, 118, 11,79411,806, doi:10.1002/2013JD020507.

[2] Balakrishnaiah, G., Reddy, B. S. K., Gopal, K. R., Reddy, R. R., Reddy, L. S. S., Swamulu, C., ... \& Babu, S. S. (2012). Spatio-temporal variations in aerosol optical and cloud parameters over Southern India retrieved from MODIS satellite data. Atmospheric environment, 47, 435-445.

[4] Bilal, M., Nichol, J.E., 2015. Evaluation of MODIS aerosol retrieval algorithms over the Beijing-Tianjin-Hebei region during low to very high pollution events. J. Geophys. Res. Atmos. 120, 7941-7957. https://doi.org/10.1002/2015JD023082. 
[5] Dey, S., Di Girolamo, L., 2011. A decade of change in aerosol properties over the Indian subcontinent. Geophys. Res. Lett. 38, L14811 https://doi.org/10.1029/ 2011 GL048153.

[6] Eck, T.F., Holben, B.N., Reid, J.S., Dubovik, O., Smirnov, A., O'neill, N.T., Slutsker, I., Kinne, S., 1999. Wavelength dependence of the optical depth of biomass burning, urban, and desert dust aerosols. J. Geophys. Res. 104 (D24), 31333-31349

[7] Gunaseelan, I., Bhaskar, B. V., \& Muthuchelian, K. (2014). The effect of aerosol optical depth on rainfall with reference to meteorology over metro cities in India. Environmental Science and Pollution Research, 21(13), 8188-8197.

[8] Hsu, N.C., Tsay, S.C., King, M.D. and Herman, J.R., 2006. Deep blue retrievals of Asian aerosol properties during ACE-Asia. IEEE transactions on geoscience and remote sensing, 44(11), 3180-3195.

[9] IPCC, 2013. Climate Change 2013: The Physical Science Basis. Contribution of Working Group I to the Fifth Assessment Report of the Intergovernmental Panel on Climate Change. Cambridge University Press, New York.

[10] Kulshrestha, U. C., \& Disha Sharma, (2015). Importance of atmospheric dust in air: Future scope of research, Journal of Indian Geophysical Union, 19(2), 205.

[11] Kumar, M.; Parmar, K.S.; Kumar, D.B.; Mhawish, A.; Broday, D.M.; Mall, R.K.; Banerjee, T.(2018) Long-term aerosol climatology over Indo-Gangetic Plain: Trend, prediction and potential source fields. Atmos. Environ. 180, 37-50.

[12] Kumar, S., Singh, A., Srivastava, A. K., Sahu, S. K., Hooda, R. K., Dumka, U. C., \& Pathak, V. (2021). Long-term change in aerosol characteristics over Indo-Gangetic Basin: How significant is the impact of emerging anthropogenic activities? Urban Climate, 38, 100880.

[13] Mehta, M., Singh, R., Singh, A., \& Singh, N. (2016). Recent global aerosol optical depth variations and trends-A comparative study using MODIS and MISR level 3 datasets. Remote sensing of environment, 181, 137-150.

[14] Mhawish, A., Sorek-Hamer, M., Chatfield, R., Banerjee, T., Bilal, M., Kumar, M., ... \& Kalashnikova, O. (2021). Aerosol characteristics from earth observation systems: A comprehensive investigation over South Asia (2000-2019). Remote Sensing of Environment, 259, 112410.

[15] Parisi, A.V.; Igoe, D.; Downs, N.J.; Turner, J.; Amar, A.; AJebar, M.A., 2021. Satellite Monitoring of Environmental Solar Ultraviolet A (UVA) Exposure and Irradiance: A Review of OMI and GOME-2. Remote Sens., 13, 752. https://doi.org/10.3390/rs13040752.

[16] Payra, S., Gupta, P., Bhatla, R., El Amraoui, L., \& Verma, S. 2021. Temporal and spatial variability in aerosol optical depth (550 $\mathrm{nm}$ ) over four major cities of India using data from MODIS onboard the Terra and Aqua satellites. Arabian Journal of Geosciences, 14(13), 1-11.

[17] Ramachandran, S., 2007. Aerosol optical depth and fine mode fraction variations deduced from Moderate Resolution Imaging Spectroradiometer (MODIS) over four urban areas in India. Journal of Geophysical Research: Atmospheres, 112(D16).

[18] Ramachandran, S., and R. Cherian (2008), Regional and seasonal variations in aerosol optical characteristics and their frequency distributions over India during 2001-2005, J. Geophys. Res., 113, D08207, doi:10.1029/2007JD008560.

[19] Ramachandran, S., Kedia, S., \& Srivastava, R. (2012). Aerosol optical depth trends over different regions of India. Atmospheric Environment, 49, 338-347. 
[20] Ramachandran, S. (2018). Aerosols and climate change: Present understanding, challenges, and future outlook. In Land-Atmospheric Research Applications in South and Southeast Asia (pp. 341-378). Springer, Cham.

[21] Remer, L.A., Kleidman, R.G., Levy, R.C., Kaufman, Y.J., Tanre, D., Mattoo, S., Martins, J.V., Ichoku, C., Koren, I., Yu, H., Holben, B.N., 2008. Global aerosol climatology from the MODIS satellite sensors. J. Geophys. Res. 113 (D14). https://doi.org/10.1029/2007JD009661.

[22] Remer, L.A., Tanré, D., Kaufman, Y.J., Levy, R. and Mattoo, S., (2006). Algorithm for remote sensing of tropospheric aerosol from MODIS: Collection 005. National Aeronautics and Space Administration, 1490.

[23] Sabetghadam, S., Khoshsima, M., Pierleoni, A., Aerosol climatology and determination of different types over the semi-arid urban area of Tehran, Iran: Application of multi-platform remote sensing satellite data, Atmospheric Pollution Research (2020), doi: https://doi.org/10.1016/j.apr.2020.06.029.

[24] Satheesh, S. K., Babu, S. S., Padmakumari, 5. B., Pandithurai, G., \& Soni, V. K. (2017). Variability of atmospheric aerosols over India. In Observed Climate Variability and Change over the Indian Region (pp. 221-248). Springer, Singapore.

[25] A. Sen, A.S. Abdelmaksoud, Y. Nazeer Ahammed, Mansour A. et al.(2017). Variations in particulate matter over Indo-Gangetic Plains and IndoHimalayan Range during four field campaigns in winter monsoon and summer monsoon: Role of pollution pathways, Atmospheric Environment, 154, 200-224.

[26] Sharma, D., \& Kulshrestha, U. (2017). Dust storms and their influence on optical and chemical properties of aerosols along north-western Indo-Gangetic Plains. Journal of Indian Geophysical Union, 21(6), 526-534.

[27] Sreekanth, V., 2013. Satellite derived aerosol optical depth climatology over Bangalore, India.Advances in Space Research, 51(12), 2297-2308.

[28] Srivastava, A. K., Dey, S., \& Tripathi, S. N. (2012). Aerosol characteristics over the Indo-Gangetic Basin: implications to regional climate. Atmospheric Aerosols-Regional Characteristics-Chemistry and Physics, 10, 47782.

[29] Srivastava, A.; Saran, S. Comprehensive study on AOD trends over the Indian subcontinent: A statistical approach. Int. J. Remote. Sens. 2017, 38, 5127-5149. 